\title{
Clival Malformations in CHARGE Syndrome
}

(D)E.S. Mahdi and (1DM.T. Whitehead

\begin{abstract}
BACKGROUND AND PURPOSE: CHARGE syndrome is a multisystemic congenital disorder, most commonly including coloboma, heart malformations, choanal atresia, developmental delay, and genital and ear anomalies. The diagnostic criteria for CHARGE syndrome have been refined with time. However, limited reports describe skull base and craniocervical junction abnormalities. Recently, a coronal clival cleft has been identified in association with CHARGE syndrome. The aim of our study was to assess the prevalence of clival pathology in CHARGE syndrome.
\end{abstract}

MATERIALS AND METHODS: In this retrospective study, the CT/MR imaging data base at a single academic children's hospital was queried for the phrase "CHARGE syndrome" during a 17-year period (2001-2017). Electronic medical records were reviewed to confirm the diagnosis. Images were assessed for skull base anomalies, specifically clival hypoplasia and dysplasia.

RESULTS: The search yielded 42 examinations ( $21 \mathrm{CTs}$ and $21 \mathrm{MRIs}$ ) from 15 distinct patients (mean age, $4.1 \pm 5.6$ years; range, 2 days to 19 years). CHARGE syndrome diagnosis was confirmed either by clinical and genetic testing $(n=6)$ or by clinical diagnosis only $(n=9)$. A coronal clival cleft was identified in $87 \%$ of patients (37 examinations, $n=13$ patients), either partial $(53 \%)$ or complete (33\%). Clival hypoplasia without clefting was present in all 5 examinations from the remaining 2 patients.

CONCLUSIONS: Clival pathology is universal in CHARGE syndrome. Coronal clival clefts are extremely common, representing a useful additional diagnostic finding. Detection of a clival cleft should alert the radiologist to examine the palate, choana, eyes, ears, and olfactory centers for other signs of CHARGE syndrome.

ABBREVIATIONS: CHARGE = Coloboma of the eye, Heart defects, Atresia of the choanae, Retardation of growth and/or development, Genital and/or urinary abnormalities, and Ear abnormalities and deafness; CHD7 = chromodomian helicase DNA-binding protein 7

C HARGE syndrome is a rare genetic disorder with widespread malformations. The acronym CHARGE includes coloboma, heart malformation, choanal atresia, retardation of growth and/or development, genital anomalies, and ear anomalies. ${ }^{1}$ Across time, there has been refinement of the diagnostic criteria to 3 major (the classic 3C's: choanal atresia, coloboma, semicircular canal hypoplasia) and 5 minor features. ${ }^{2,3}$ The prevalence of CHARGE syndrome was estimated to be $1 / 8500$ live births by the Canadian Pediatric Surveillance Program. ${ }^{4}$ The discovery of a CHARGE syndrome-associated gene, CHD7 (chromodomain helicase DNA-binding protein 7, MIM 608892), has greatly as-

Received November 11, 2017; accepted after revision February 5, 2018

From the Department of Diagnostic Imaging and Radiology (E.S.M., M.T.W.), Children's National Medical Center, Washington, DC; and George Washington University Hospital (M.T.W.), Washington, DC.

Please address correspondence to Eman S. Mahdi, MD, Department of Radiology, Children's National Health System, 111 Michigan Ave NW, Washington, DC 20010;

e-mail: emahdi@childrensnational.org

三 Indicates article with supplemental on-line table.

http://dx.doi.org/10.3174/ajnr.A5612 sisted syndromic prevalence estimations due to the phenotypic diversity of the disease. ${ }^{5}$ Mutations of the $\mathrm{CHD} 7$ gene are present in two-thirds of patients with CHARGE syndrome. Phenotype and genotype correlation are required to better assess this syndrome. ${ }^{6}$ The skull base and craniocervical junction abnormalities are often underrecognized in CHARGE syndrome. Detection of these osseous abnormalities should alert the radiologist to examine the palate, choana, eyes, ears, and olfactory centers for other signs of CHARGE syndrome. Recently, a coronal clival cleft has been identified in association with CHARGE syndrome. ${ }^{7}$ The aim of our study was to assess the prevalence of clival pathology including clival clefts in patients with CHARGE syndrome.

\section{MATERIALS AND METHODS Subjects}

A retrospective study was performed after institutional review board approval with Health Insurance Portability and Accountability Act compliance. Requirement for informed consent was waived. The imaging data base at a single academic children's hospital was queried for the term "CHARGE syn- 
drome" provided by the history or by the suspected radiologic findings after filtering by technique (CT and MR imaging) during a 17-year period (2001-2017). Review of the electronic

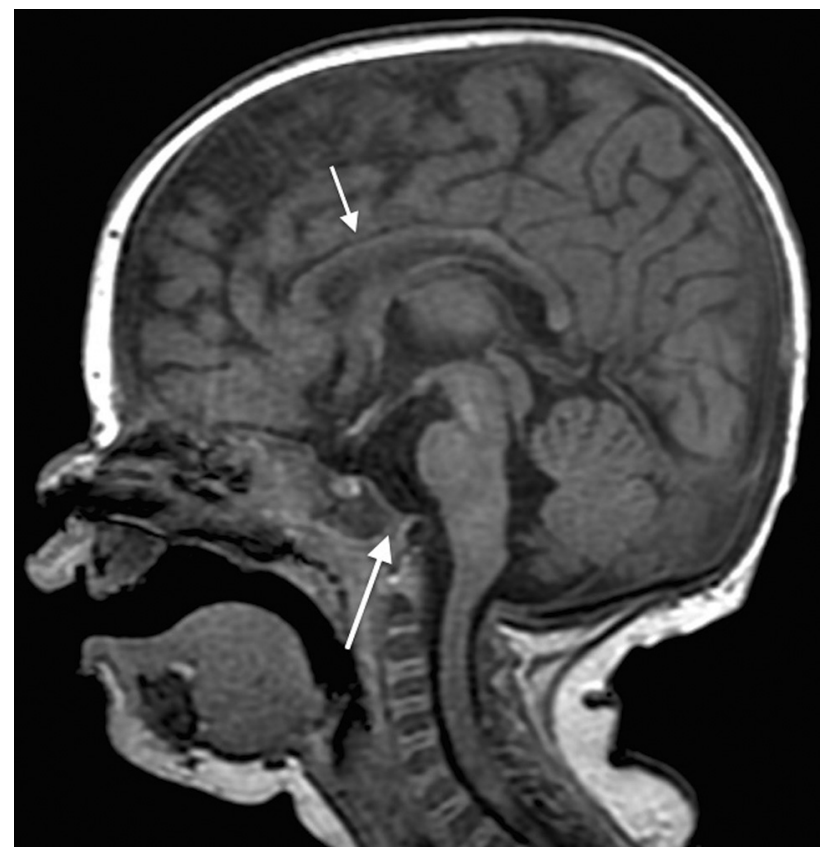

FIG 1. Midline sagittal spoiled gradient-recalled acquisition TIWI (1.5T MR imaging; TR $/ \mathrm{TE}=11 / 5.1 \mathrm{~ms} ; \mathrm{TI}=500 \mathrm{~ms}$; slice thickness $=1.5 \mathrm{~mm}$ ) from a 3-month-old girl with CHARGE syndrome shows a distinctive complete coronally oriented clival cleft in the basiocciput (large arrow). Also note mild thinning of the corpus callosum (small arrow), cerebellar vermian hypoplasia, and brain stem volume loss. medical records of all patients was performed to confirm the diagnosis and symptomatology. Images were assessed for skull base anomalies, specifically clival hypoplasia/dysplasia and coronal clival cleft.

\section{Imaging Characteristics}

All examinations were of diagnostic quality. MR imaging studies were performed on either $1.5 \mathrm{~T}$ or $3 \mathrm{~T}$ scanners (Discovery MR 750 and 450; GE Healthcare, Milwaukee, Wisconsin). Sagittal T1WI, axial T2WI, axial T2 fluid-attenuated inversion recovery imaging, coronal fat-saturated T2WI, and axial DTI with 7 noncollinear directions of encoding were reviewed. Axial T1WI and coronal fat-saturated T1WI of the brain were also performed in 5 MRIs after IV gadolinium administration in 5 different patients $(0.1 \mathrm{mmol} / \mathrm{kg}$ of either gadoterate meglumine $[n=2]$ or gadopentetate dimeglumine $[n=3])$. CT images of the head, temporal bone, facial bone, sinuses, and/or cervical spine were acquired on a 16-detector row scanner (GE Healthcare). Studies were reviewed in a blinded manner by a qualified pediatric neuroradiologist (M.T.W.) with $>5$ years of experience. Imaging studies were qualitatively examined for all visible abnormalities involving the brain, ocular and olfactory systems, temporal bones, cleft lip/palate, and the presence of clival abnormalities.

\section{RESULTS}

\section{Characteristics of the Cohort}

The search yielded 17 patients with a history or suspected radiologic findings of CHARGE syndrome. Two patients lacking diagnostic confirmation were excluded. The final cohort comprised 42 examinations (21 CTs and 21 MRIs) from 15 patients (mean
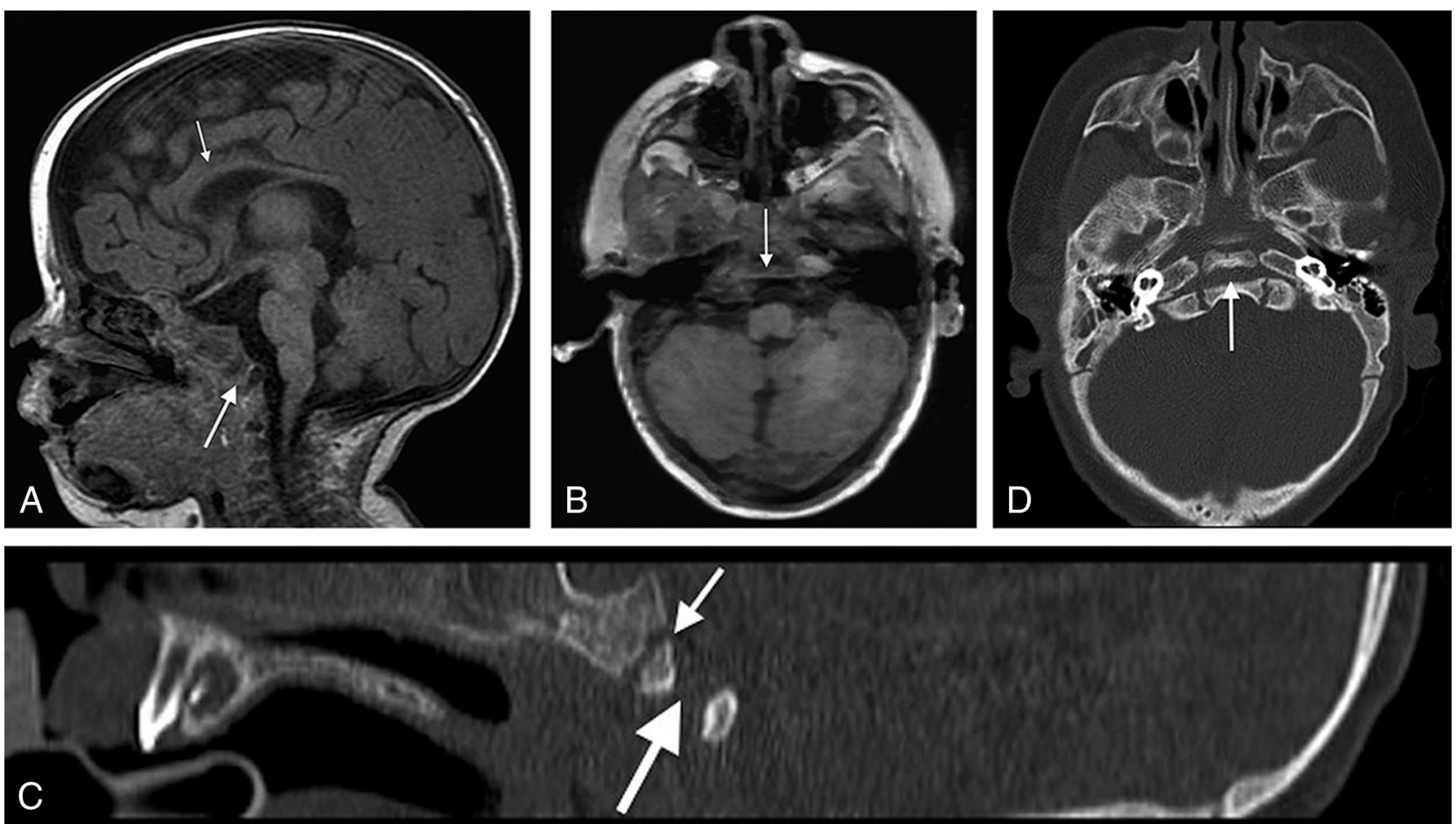

FIG 2. A, Midline sagittal spoiled gradient-recalled acquisition TIWI (1.5T MR imaging; TR/TE $=12 / 5 \mathrm{~ms} ; \mathrm{TI}=500 \mathrm{~ms}$; slice thickness $=2 \mathrm{~mm})$ from a 4-month-old girl with CHARGE syndrome shows a complete coronally oriented clival cleft in the basiocciput (large arrow). Also note thinning of the corpus callosum (small arrow), cerebellar vermian hypoplasia, and brain stem volume loss. B, Axial spoiled gradient-recalled acquisition of the same patient shows a coronally oriented cleft traversing the clivus (arrow). Corresponding sagittal (C) and axial (D) CT images demonstrate the complete cleft (large arrow) as distinct from the normal spheno-occipital synchondrosis (small arrow in C). 

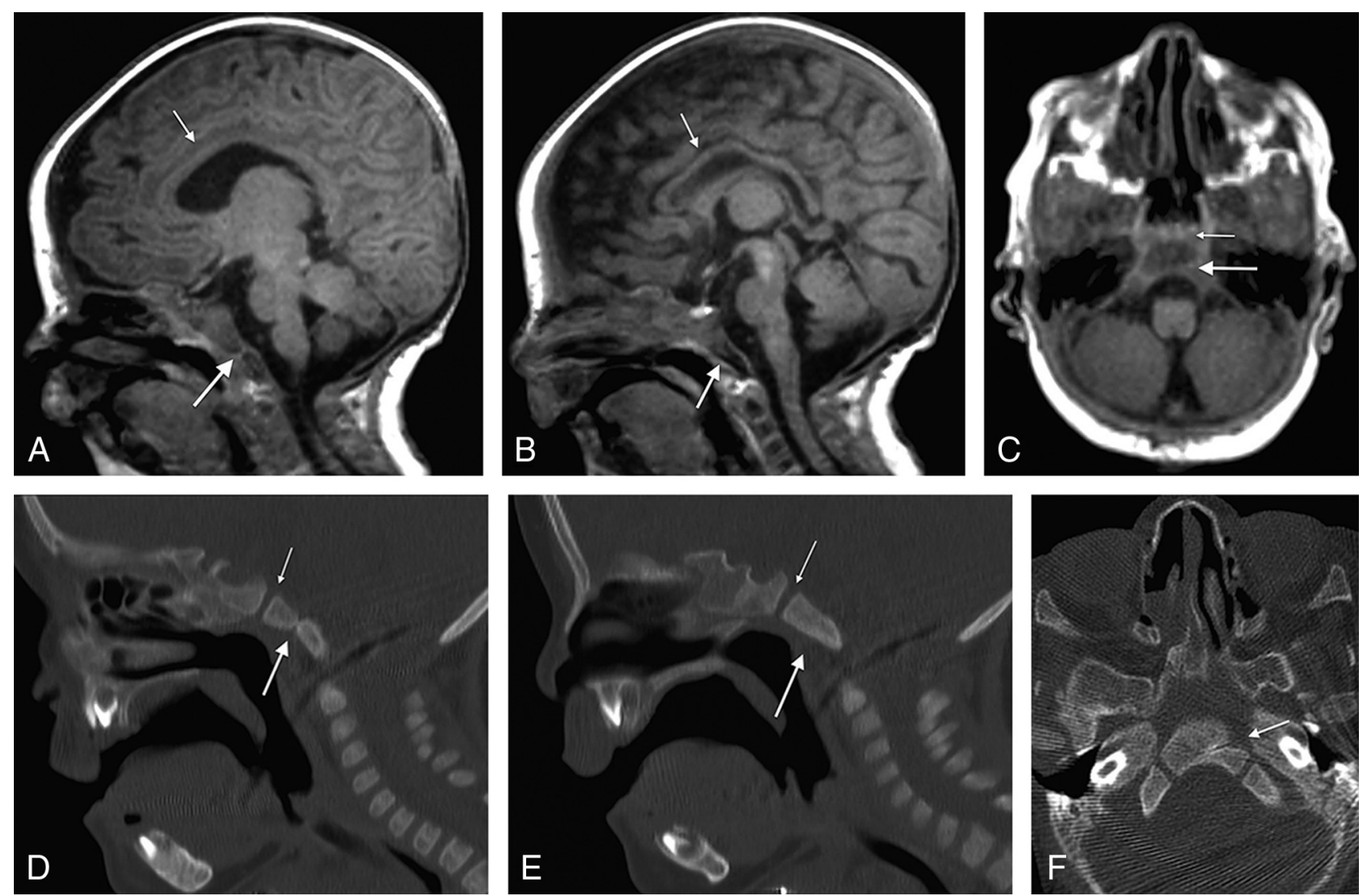

FIG 3. Spoiled gradient-recalled acquisition TIWI (3T MR imaging; TR/TE $=6.6 / 2.5 \mathrm{~ms} ; \mathrm{TI}=700 \mathrm{~ms}$; slice thickness $=0.63 \mathrm{~mm}$ ) from a 34 -day-old boy with CHARGE syndrome shows a partial (unilateral left side) coronally oriented clival cleft in the basiocciput. A, Left parasagittal unilateral clival cleft (large arrow), mild thinning of the corpus callosum (small arrow), cerebellar vermian hypoplasia, and brain stem volume loss are illustrated. B, Right parasagittal image shows a normal appearance of the clivus without clefting, a thin corpus callosum (small arrow), and vermian and brain stem hypoplasia. C, Axial TTWI of the same patient with a left-sided cleft (large arrow) and normal spheno-occipital synchondrosis (small arrow). Corresponding sagittal and axial CT images ( $D$ and $F$ ) further demonstrate the unilateral left clival cleft (large arrow, $D$ and $F$ ) and absence of clival clefting on the contralateral side $(E)$. Note normal spheno-occipital synchondrosis (small arrow, $D$ and $E$ ).

age, $4.1 \pm 5.6$ years; range, 2 days to 19 years); 3 patients were older than 11 years at the time of imaging.

Diagnosis of CHARGE syndrome was confirmed by either clinical and genetic testing $(n=6)$ or clinical diagnosis only $(n=$ 9). ${ }^{2,3}$ Fifty-three percent of the patients were male $(n=8)$.

\section{Clival Imaging Findings}

A coronal clival cleft was identified in $87 \%$ of patients (37 examinations, $n=13$ patients), either complete (33\%, $n=5)$ (Figs 1 and 2) or partial (53\%, $n=8$ ) (Fig 3). Clival hypoplasia without clefting was present in all 5 examinations from the remaining 2 patients (On-line Table). ${ }^{8}$ Those with a partial cleft were further characterized as having either a unilateral cleft in 25\% $(n=2)$ (Fig 3 ) or bilateral cleft with minimal central fusion in $75 \%(n=6)$.

\section{Clival Clefting/Hypoplasia and CHD7 Mutation}

The clival findings were further stratified according to the CHD7 mutation. Those with $C H D 7$ mutation $(n=6)$ had an equal number of complete and partial clival clefts $(50 \%, n=3)$ of each type. Those with a non-CHD7-confirmed clinical diagnosis $(n=9)$ were variable (partial cleft, $n=5$; complete cleft, $n=2$; and clival hypoplasia, $n=2$ ).

Other imaging features pertinent to the diagnosis of CHARGE syndrome affecting the eye, olfactory apparatus, ears, and brain are classified in the On-line Table.

\section{DISCUSSION}

CHARGE syndrome is a systemic disorder with multiorgan involvement. Specific organ abnormalities include cardiac (75\%-80\%, including atrial septal defect, ventricular septal defect, patent ductus arteriosus, tetralogy of Fallot, atrioventricular canal defect, and double outlet right ventricle), ${ }^{9}$ genitourinary (including hypospadias; penile agenesis; bifid scrotum; cryptorchidism; atresia of the vagina, cervix, and uterus; renal hypoplasia; solitary kidney; hydronephrosis; vesicoureteral reflux; and duplex kidneys), ${ }^{9}$ ocular (80\%, including coloboma of the iris, retina-choroid, and/or disc; and microphthalmos), ${ }^{9}$ ear (80\%$100 \%$, including external ear dysmorphology; incus hypoplasia; decreased number of cochlear turns; and absent semicircular canals), ${ }^{9,10}$ olfactory (100\%, including unilateral or bilateral absence or hypoplasia of the olfactory bulbs or sulci), ${ }^{9,11}$ choanal atresia (50\%$60 \%),{ }^{12}$ orofacial (15\%-20\%, including cleft lip/palate), ${ }^{9}$ brain (including corpus callosum agenesis; posterior fossa anomalies; cranial nerve dysfunction; and cerebellar vermis hypoplasia), ${ }^{12,13}$ and osseous anomalies (skull base and craniocervical junction)..$^{9,8,14}$ Prenatal diagnosis of CHARGE syndrome has been reported through the finding of CHD7 mutations on chorionic villus sampling and ultrasonographic findings of hydramnios, choanal atresia, tracheoesophageal fistula, and semicircular canal agenesis. ${ }^{15,16}$

AJNR Am J Neuroradiol 39:1153-56 Jun 2018 www.ajnr.org 1155 
Craniocervical junction abnormalities are common in CHARGE syndrome. Fujita et $\mathrm{al}^{8}$ demonstrated a high prevalence of basioccipital hypoplasia and basilar invagination in CHARGE syndrome and recommended routine assessment of these anomalies to exclude a life-threatening basilar invagination. Natung et $\mathrm{al}^{14}$ reported a case of basilar invagination, short clivus, fused cervical vertebrae, and occipitalization of the atlas. A recent case report of a coronal clival cleft has been identified in association with CHARGE syndrome. ${ }^{7}$ Recently, Hoch et $\mathrm{al}^{17}$ described a dorsally angulated clivus with posterior displacement of an ossific density in 7 of 10 patients with CHARGE syndrome. The dominant findings we have described herein, namely partial and complete coronal clival clefting, correspond to the description and imaging depictions that those authors provided and further emphasize the importance of craniocervical junction anomalies in CHARGE syndrome.

The pathogenesis of these anomalies in CHARGE syndrome is not clearly understood. They likely originate in the first trimester, concurrent with other CHARGE malformations. ${ }^{18}$ The $C H D 7$ gene encoding chromodomain helicase DNA-binding protein 7 (CHD7 protein) may play a role through the assumption of the interaction between the neural crest and somite cells, which are responsible for formation of the basiocciput during development. ${ }^{19,20}$

The clivus is formed from 2 main components, the upper basisphenoid and the lower basiocciput. The 2 are separated by the normal spheno-occipital synchondrosis. The basiocciput is formed from 4 occipital sclerotomes. ${ }^{19}$ The clivus reaches the full developmental length by 11 years of age. ${ }^{21}$ Clival clefts occur caudal to and distinct from the spheno-occipital synchondrosis, which usually fuses between 12 and 18 years of age. ${ }^{19}$ The presence of normal anatomic variants such as clival canal/foramen, fossa navicularis magna, or basilar transverse fissure (Sauser fissure) should not be confused with a clival cleft. ${ }^{22-24}$ Although the etiology of coronal clival clefts is unknown, these clefts could be related to incomplete fusion of clival ossification centers, enlarged clival canals (fossa navicularis), or persistence of basilar transverse fissure. ${ }^{19,22-24}$

This study has some limitations by being retrospective and having a relatively small sample size. Despite these limitations, to date, it is the largest study to describe and illustrate clival pathology and clefting in CHARGE syndrome.

\section{CONCLUSIONS}

Clival pathology is universal in CHARGE syndrome. Coronal clival clefts are extremely common, representing a useful diagnostic feature and should be considered an additional finding in CHARGE syndrome. The skull base should be scrutinized for these characteristic anomalies. Detection of a clival cleft should alert the radiologist to examine the palate, choana, eyes, ears, and olfactory centers for other signs of CHARGE syndrome.

\section{REFERENCES}

1. Pagon RA, Graham JM Jr, Zonana J, et al. Coloboma, congenital heart disease, and choanal atresia with multiple anomalies: CHARGE association. J Pediatr 1981;99:223-27 CrossRef Medline
2. Verloes A. Updated diagnostic criteria for CHARGE syndrome: a proposal. Am J Med Genet A 2005;133A:306-08 CrossRef Medline

3. Blake KD, Davenport SL, Hall BD, et al. CHARGE association: an update and review for the primary pediatrician. Clin Pediatr (Phila) 1998;37:159-73 CrossRef Medline

4. Issekutz KA, Graham JM Jr, Prasad C, et al. An epidemiological analysis of CHARGE syndrome: preliminary results from a Canadian study. Am J Med Genet A 2005;133A:309-17 CrossRef Medline

5. Vissers LE, van Ravenswaaij CM, Admiraal R, et al. Mutations in a new member of the chromodomain gene family cause CHARGE syndrome. Nat Genet 2004;36:955-57 CrossRef Medline

6. Sanlaville D, Verloes A. CHARGE syndrome: an update. Eur J Hum Genet 2007;15:389-99 CrossRef Medline

7. Mahdi E, Whitehead MT. Coronal clival cleft in CHARGE syndrome. Neuroradiol J 2017;30:574-77 CrossRef Medline

8. Fujita K, Aida N, Asakura Y, et al. Abnormal basiocciput development in CHARGE syndrome. AJNR Am J Neuroradiol 2009;30: 629-34 CrossRef Medline

9. Blake KD, Prasad C. CHARGE syndrome. Orphanet J Rare Dis 2006; 1:34 CrossRef

10. Morimoto AK, Wiggins RH 3rd, Hudgins PA, et al. Absent semicircular canals in CHARGE syndrome: radiologic spectrum of findings. AJNR Am J Neuroradiol 2006;27:1663-71 Medline

11. Blustajn J, Kirsch CF, Panigrahy A, et al. Olfactory anomalies in CHARGE syndrome: imaging findings of a potential major diagnostic criterion. AJNR Am J Neuroradiol 2008;29:1266-69 CrossRef Medline

12. Lalani SR, Hefner MA, Belmont JW, et al. CHARGE syndrome. In: Adam MP, Ardinger HH, Pagon RA, et al, eds. GeneReviews. Seattle: University of Washington; 1993-2018 Medline

13. Yu T, Meiners LC, Danielsen K, et al. Deregulated FGF and homeotic gene expression underlies cerebellar vermis hypoplasia in CHARGE syndrome. Elife 2013;2:e01305 CrossRef Medline

14. Natung T, Goyal A, Handique A, et al. Symmetrical chorioretinal colobomata with craniovertebral junction anomalies in CHARGE syndrome: a case report with review of literature. J Clin Imaging Sci 2014;4:5 CrossRef Medline

15. Becker R, Stiemer B, Neumann L, et al. Mild ventriculomegaly, mild cerebellar hypoplasia and dysplastic choroid plexus as early prenatal signs of CHARGE association. Fetal Diagn Ther 2001;16:280-83 CrossRef Medline

16. Hertzberg BS, Kliewer MA, Lile RL. Antenatal ultrasonographic findings in the CHARGE association. J Ultrasound Med 1994;13: 238-42 CrossRef Medline

17. Hoch MJ, Patel SH, Jethanamest D, et al. Head and neck MRI findings in CHARGE syndrome. AJNR Am J Neuroradiol 2017;38: 2357-63 CrossRef Medline

18. Sanlaville D, Etchevers HC, Gonzales M, et al. Phenotypic spectrum of CHARGE syndrome in fetuses with CHD7 truncating mutations correlates with expression during human development. $J$ Med Genet 2006;43:211-17 CrossRef Medline

19. Smoker WR. Craniovertebral junction: normal anatomy, craniometry, and congenital anomalies. Radiographics 1994;14:255-77 CrossRef Medline

20. Nie X. Cranial base in craniofacial development: developmental features, influence on facial growth, anomaly, and molecular basis. Acta Odontol Scand 2005;63:127-35 CrossRef Medline

21. Krmpotić-Nemanić J, Vinter I, Kelovizć Z, et al. Postnatal changes of the clivus. Ann Anat 2005;187:277-80 CrossRef Medline

22. Inal M, Muluk NB, Ozveren MF, et al. The presence of clival foramen through multidetector computed tomography of the skull base. $J$ Craniofac Surg 2015;26:e580-82 CrossRef Medline

23. Beltramello A, Puppini G, El-Dalati G, et al. Fossa navicularis magna. AJNR Am J Neuroradiol 1998;19:1796-98 Medline

24. Hofmann E, Prescher A. The clivus: anatomy, normal variants and imaging pathology. Clin Neuroradiol 2012;22:123-39 CrossRef Medline 